American Journal of Applied Sciences 7 (6): 829-834, 2010

ISSN 1546-9239

(C) 2010Science Publications

\title{
Effect of Different Uniform Temperature with Thickness-Wise Linear Temperature Gradient on Interfacial Stresses of a Bi-Material Assembly
}

\author{
${ }^{1}$ D. Sujan, ${ }^{1}$ Z.Oo, ${ }^{2}$ M.V.V. Murthy and ${ }^{3}$ K.N. Seetharamu \\ ${ }^{1}$ School of Engineering and Science, Curtin University of Technology, Sarawak, Malaysia \\ ${ }^{2}$ Quest, Bangalore 560085, India \\ ${ }^{3}$ Department of Thermal Engineering, PES Institute of Technology, \\ 100 Feet Ring Road, BSK III Stage, Bangalore 560085, India
}

\begin{abstract}
Problem statement: The thermal mismatch induced interfacial stresses are one of the major reliability issues in electronic packaging and composite materials. Consequently an understanding of the nature of the interfacial stresses under different temperature conditions is essential in order to eliminate or reduce the risk of structural and functional failure. Approach: In this analysis, a model was proposed for the shearing and peeling stresses occurring at the interface of two bonded dissimilar materials with the effect of different uniform temperatures in the layers. The model was then upgraded by accounting thickness wise linear temperature gradients in the layers using two temperature drop ratios. The upgraded models were then compared with the existing uniform temperature model. The proposed model can be seen as a more generalized form to predict interfacial stresses at different temperature conditions that may occur in the layers. Results: The results were presented for an electronic bi-material package consisting of die and die-attach. Conclusion: The numerical simulation is in a good matching agreement with analytical results.
\end{abstract}

Key words: Shearing stress, peeling stress, different uniform temperature, thickness wise linear temperature gradient

\section{INTRODUCTION}

Thermo-mechanical stresses are the major contributor to the structural failure between two bonded layered structure (for instance, between a device and a substrate). These stresses can lead to mechanical (structural) as well as functional (electrical or optical) failure to the field of microelectronics and photonic components and devices (Suhir, 2009). Consequently an understanding of the nature of the interfacial stresses under different temperature conditions is necessary in order to minimize or eliminate the risk of structural failure.

A thermally mismatched stressed model is widely analyzed using a bi-material thermostat. Timoshenko (1925) initiated a fundamental solution to thermal stresses of bi-metal thermostats using the beam theory in 1925 . Suhir $(1986 ; 1989)$ proposed relatively simple and easy-to-use interfacial thermal stress model compared to the early model proposed by Timoshenko (1925). Many more researchers have modified, upgraded and/or corrected bi-material model to the present simplified form in the last few decades (Timoshenko, 1925; Suhir, 1986; 1989; Matthys and
Mey, 1996; Mirman, 1991; Moore and Jarvis, 2003; 2004; Ru, 2002). However, most research works on this direction focused on thermal mismatch stresses subjected to uniform temperature changes in the layers. But in reality, temperature levels in the two bonded layers should be different during manufacturing, curing, or even operating due to the dissimilarity of the materials. Moreover, with the existence of heat flow in the materials (for instance, die), there may also exist temperature gradient in the layers. Thus the effect of the existence of different uniform temperatures with temperature gradients in the layers may influence the shearing and peeling stresses along the interface. Hardly, any analytical study has been carried out earlier in this direction.

In the present analysis the authors have extended Suhir (1986) uniform temperature shearing stress model by introducing a temperature ratio parameters $\mathrm{m}\left(=\Delta \mathrm{T}_{2} / \Delta \mathrm{T}_{1}\right)$ to account for different uniform temperatures in the layers, where $\mathrm{i}=1,2$ and $\mathrm{T}_{\mathrm{i}}$ represents the temperature of the $\mathrm{i}$-th layer. Subsequently a model is proposed for peeling stress at the interfaces using the proposed different uniform temperature shearing stress model. The different 
uniform temperature shearing and peeling stress models are then further upgraded with the consideration of linear temperature gradients in the layers by incorporating two temperature drop ratios $\beta_{1}\left\{\left\{=\left(\Delta \mathrm{T}_{1}-\Delta \mathrm{T}_{1}^{\prime}\right) / \Delta \mathrm{T}_{1}^{\prime}\right\}\right.$ and $\quad \beta_{2}\left\{\left\{=\left(\Delta \mathrm{T}_{2}-\Delta \mathrm{T}_{2}^{\prime}\right) / \Delta \mathrm{T}_{2}^{\prime}\right\}\right.$ in the layers, $T_{i}^{\prime}$ represents the temperature at the top surface of i-th layer. As a result a more generalized model is developed which is able to take care of different temperature conditions in the layers.

Analytical formulation: The uniform temperature shearing stress model is presented here by solving a simple second order differential equation instead of a relatively complicated integro-differential equation of Suhir's one (Suhir, 1986). The model is then upgraded with different uniform temperatures in the two layers and subsequently thickness wise linear temperature gradients are incorporated in the layers to complete the generalized form.

Figure1 represents the full length of the 2-D uniform temperature model where AA showing the line of symmetry. The 2-D model is considered to be of unit width in a direction perpendicular to the paper and all forces and moments are defined with respect to the unit width. E, $\alpha, v$ and $h$ represent elastic modulus, thermal expansion coefficient, Poisson's ratio and thickness of the $\mathrm{i}$-th layer and $\Delta \mathrm{T}$ uniform temperature change in the layers.

The compatibility condition at the interface can be expressed as:

$$
\mathrm{U}_{\mathrm{x}(1)}-\mathrm{U}_{\mathrm{x}(2)}=0
$$

where, $\mathrm{U}_{\mathrm{i}}, \mathrm{i}=1,2$ are the axial displacements for the layers.

In the present approach, the above condition is expressed in its following simpler form:

$\epsilon_{\mathrm{x}(1)}=\in_{\mathrm{x}(2)}$

where, $\epsilon_{x(i)}, i=1,2$ are the axial strains given by:

$$
\epsilon_{\mathrm{x}(\mathrm{i})}=\frac{\partial \mathrm{U}_{\mathrm{i}}}{\partial \mathrm{x}}
$$

The conditions (1) and (2) are mathematically equivalent. Suhir (1986) used Eq. 1 as the compatibility condition which required solving a complicated integrodifferential equation.
Considering moment equilibrium about positive Zaxis at $\mathrm{x}$ and $\mathrm{y}=0$, the expression for radius of curvature is expressed as:

$\frac{1}{R}=\frac{\left(h_{1}+h_{2}\right)}{2\left(D_{1}+D_{2}\right)} F=\frac{h F}{2 D}$

where, $D_{i}, i=1,2$ are Flexural rigidity, $D_{i}=\frac{E_{i} h_{i}^{3}}{12\left(1-v_{i}^{2}\right)}$.

Different uniform temperature shearing stress model: With the introduction of differential uniform temperatures $\Delta \mathrm{T}_{1}$ and $\Delta \mathrm{T}_{2}$ in layer 1 and layer 2 respectively in Fig. 1, the axial strains at the interface take the form as:

$\epsilon_{\mathrm{x}(1)}=\alpha_{1} \Delta \mathrm{T}_{1}+\lambda_{1} \mathrm{~F}_{1}+\frac{\mathrm{h}_{1}}{2 \mathrm{R}}-\mathrm{K}_{1} \frac{\partial \tau}{\partial \mathrm{x}}$

$\left.\epsilon_{\mathrm{x}(2)}=\alpha_{2} \Delta \mathrm{T}_{2}-\lambda_{2} \mathrm{~F}_{2}-\frac{\mathrm{h}_{2}}{2 \mathrm{R}}+\mathrm{K}_{2} \frac{\partial \tau}{\partial \mathrm{x}}\right\}$

where, $\alpha_{i} \Delta T_{i}, \lambda_{i} F_{i}, \frac{h_{i}}{2 R}$ and $K_{i} \frac{\partial \tau}{\partial x}$, are the strain components due to temperature changes, thermal mismatch axial forces $F_{i}$, bending and shearing forces respectively.

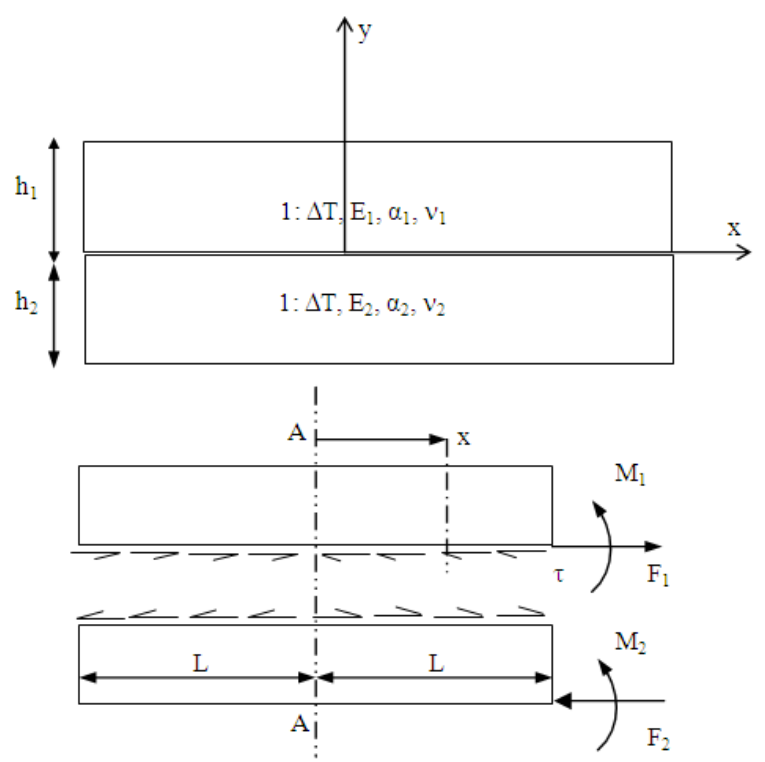

Fig. 1: Geometrical and material parameters with free body diagram of the uniform temperature model 
In Eq. $4, \mathrm{~K}_{\mathrm{i}}, \mathrm{i}=1,2$ are interfacial shear compliances given by $\mathrm{K}_{\mathrm{i}}=\frac{\mathrm{h}_{\mathrm{i}}}{3 \mathrm{G}_{\mathrm{i}}}, \mathrm{G}_{\mathrm{i}}, \mathrm{i}=1,2$ are shear modulus of rigidities given by $G_{i}=\frac{E_{i}}{2\left(1+v_{i}\right)}$ and $\lambda_{i}$, $\mathrm{i}=1,2$ are axial compliances given by $\lambda_{\mathrm{i}}=\frac{\left(1-v_{\mathrm{i}}^{2}\right)}{\mathrm{E}_{\mathrm{i}} \mathrm{h}_{\mathrm{i}}}$.

The compatibility of axial strains at the interface in Eq. 2 demands the following condition(s):

$$
\left(\alpha_{1} \Delta T_{1}-\alpha_{2} \Delta T_{2}\right)+\lambda F-K \frac{\partial \tau}{\partial x}=0
$$

Where:

$\lambda=\lambda_{1}+\lambda_{2}+\frac{\mathrm{h}^{2}}{4 \mathrm{D}}$

$\mathrm{K}=\mathrm{K}_{1}+\mathrm{K}_{2}, \mathrm{~F}_{1}=-\mathrm{F}_{2}=\mathrm{F}$

Differentiating Eq. 5, one gets a second order differential equation in $\tau$ as follows:

$\frac{\partial^{2} \tau}{\partial x^{2}}-\kappa^{2} \tau=0$

where, $\kappa^{2}=\frac{\lambda}{\mathrm{K}}$.

The solution of this equation is assumed to be the form (Brown, 1999):

$\tau=\mathrm{C}_{1} \sinh \mathrm{Kx}+\mathrm{C}_{2} \cosh \mathrm{Kx}$

Using Eq. 7 and 6 has a solution for shearing stress $\tau(\mathrm{x})$ as follows:

$\tau=\frac{\left(\alpha_{1} \Delta \mathrm{T}_{1}-\alpha_{2} \Delta \mathrm{T}_{2}\right)}{\mathrm{K} \kappa \cosh \kappa \mathrm{L}} \sinh \kappa \mathrm{x}$

Introducing two parameters $\mathrm{m}=\frac{\Delta \mathrm{T}_{2}}{\Delta \mathrm{T}_{1}}$ and $\mathrm{n}=\frac{\alpha_{2}}{\alpha_{1}}$, Eq. 8 can be expressed as:

$\tau=\frac{\alpha_{1} \Delta \mathrm{T}_{1}(1-\mathrm{mn})}{\mathrm{K} \kappa \cosh (\kappa \mathrm{L})} \sinh (\kappa \mathrm{x})$

Formation of different uniform temperature Peeling stress model: The peeling stress $\mathrm{P}(\mathrm{x})$ (normal stress at the interface) is obtained from the consideration of moment equilibrium and $\tau(\mathrm{x})$ given by Eq. 9 .

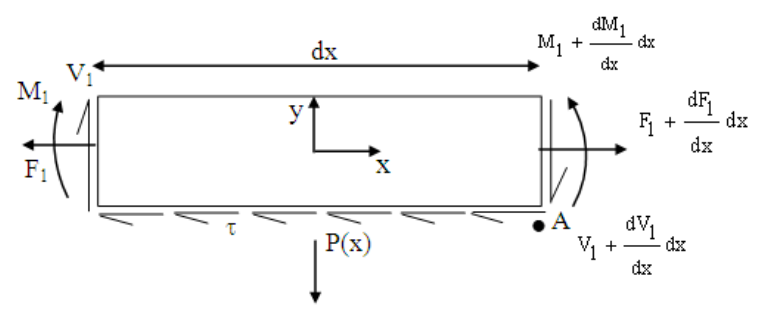

Fig. 2: Force distribution in an infinitesimal element of layer 1

Consider an infinitesimal element of layer 1 as shown in Fig. 2, for equilibrium condition of forces in the vertical direction, $\sum \mathrm{F}_{\mathrm{y}}=0$.

From where:

$P=-\frac{d V_{1}}{d x}$

Taking moment about A:

$V_{1} d x+\frac{d F}{d x} d x \frac{h_{1}}{2}-\frac{d M_{1}}{d x} d x=0$

Now using the value of $\frac{1}{R}$ from Eq. 3 and 11 becomes:

$V_{1}=a \frac{d F}{d x}$

where, $\mathrm{a}=\frac{\mathrm{D}_{1} \mathrm{~h}_{2}-\mathrm{D}_{2} \mathrm{~h}_{1}}{2 \mathrm{D}}$.

Differentiating Eq. 12 and replacing in Eq. 9 produces:

$P=-\frac{d V_{1}}{d x}=-a \frac{d \tau}{d x}$

Finally using Eq. 9 and 13 becomes:

$\mathrm{P}=\frac{\left(\mathrm{h}_{1} \mathrm{D}_{2}-\mathrm{h}_{2} \mathrm{D}_{1}\right)}{2 \mathrm{D}} \frac{\alpha_{1} \Delta \mathrm{T}_{1}(1-\mathrm{mn})}{\mathrm{K} \cosh \kappa \mathrm{L}} \cosh \kappa \mathrm{x}$

Thus, the shearing stress $\tau(\mathrm{x})$ and the peeling stress $\mathrm{P}(\mathrm{x})$ at the interface can be determined analytically using Eq. 9 and 14, respectively, for a given temperature ratio, $\mathrm{m}$. It can be observed that when the temperatures are same in both materials, the Eq. 9 and 14 corresponds to Suhir's uniform temperature shearing and peeling stress models as follows: 


$$
\begin{gathered}
\tau=\frac{\Delta T\left(\alpha_{1}-\alpha_{2}\right)}{K \kappa \cosh (\kappa \mathrm{L})} \sinh (\kappa \mathrm{x}) \\
\mathrm{P}=\frac{\left(\mathrm{h}_{1} \mathrm{D}_{2}-\mathrm{h}_{2} \mathrm{D}_{1}\right)}{2 \mathrm{D}} \frac{\Delta \mathrm{T}\left(\alpha_{1}-\alpha_{2}\right)}{\kappa \cosh (\kappa \mathrm{L})} \cosh (\kappa \mathrm{x})
\end{gathered}
$$

Upgrading different uniform temperature model with thickness wise linear temperature gradients: Figure 3 represents thickness wise linear temperature distribution, where $\Delta \mathrm{T}_{1}$ to $\Delta \mathrm{T}_{1}{ }^{\prime}$ and $\Delta \mathrm{T}_{2}$ to $\Delta \mathrm{T}_{2}{ }^{\prime}$ represent linear temperature gradients in the $\mathrm{i}$-th layer. The temperature distribution in layer 1 of Fig. 3 can be viewed as shown in Fig. 4.

Let the total change of curvature of the assembly due to change of temperature be $\frac{1}{\mathrm{R}_{(\mathrm{T})}}$; where (T) denotes temperature change. Referring to Fig. 4, the changes of curvature due to linear variation of temperature for layer 1 and layer 2 can be represented as follows:

$$
\frac{1}{\mathrm{R}_{1(\mathrm{~T})}}=\frac{\alpha_{1}}{\mathrm{~h}_{1}}\left(\Delta \mathrm{T}_{1}-\Delta \mathrm{T}_{1}^{\prime}\right)
$$

and

$$
\frac{1}{\mathrm{R}_{2(\mathrm{~T})}}=\frac{\alpha_{2}}{\mathrm{~h}_{2}}\left(\Delta \mathrm{T}_{2}-\Delta \mathrm{T}_{2}^{\prime}\right)
$$

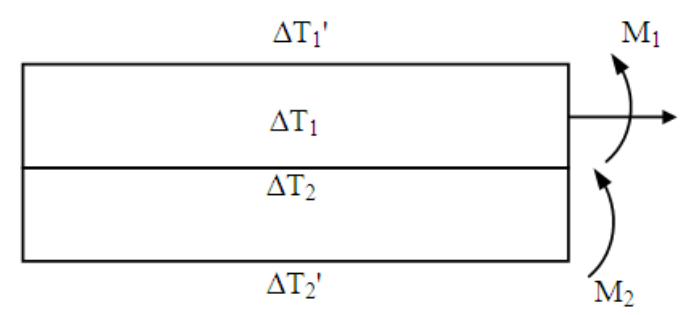

Fig. 3: Thickness wise linear temperature gradients in the layers

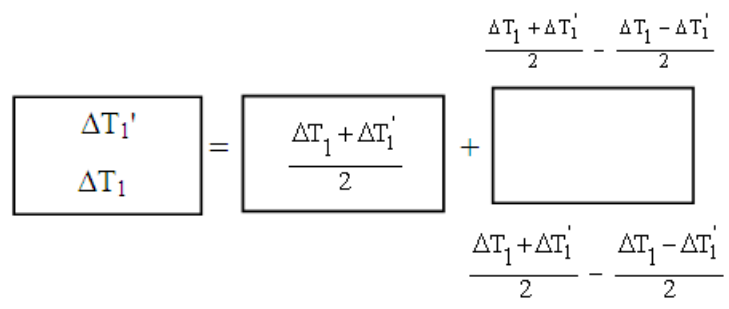

Fig. 4: Temperature distribution in layer 1 reflecting linear temperature gradient in the layer
It can be noted that $R_{1}(T)$ and $R_{2}(T)$ are the radii of curvature of the two layers induced by gradients in changes of temperature only, if allowed to expand freely. But they are bonded and hence assume the same radius of curvature, $\mathrm{R}$.

So:

$$
\frac{1}{R}=\frac{1}{R_{1(T)}}+\frac{M_{1}}{D_{1}}=\frac{1}{R_{2(T)}}+\frac{M_{2}}{D_{2}}
$$

Using $M_{i}=\frac{D_{i}}{R}$ and Eq. 3 and 15 reduces to:

$$
\frac{1}{\mathrm{R}}=\frac{1}{\mathrm{R}_{1(\mathrm{~T})}}\left(\frac{\mathrm{D}_{1}}{\mathrm{D}}\right)+\frac{1}{\mathrm{R}_{2(\mathrm{~T})}}\left(\frac{\mathrm{D}_{2}}{\mathrm{D}}\right)+\frac{\mathrm{hF}}{2 \mathrm{D}}
$$

Now considering this modified value of $\frac{1}{R}$ in Eq. 16, 9 and 14 can be reconstructed as follows:

$\tau=\frac{\alpha_{1} \Delta \mathrm{T}_{1}\left(1-\mathrm{mn}+\beta_{1} \gamma_{1}-\mathrm{mn} \beta_{2} \gamma_{2}\right)}{\mathrm{K} \kappa \cosh (\kappa \mathrm{L})} \sinh (\kappa \mathrm{x})$

$\mathrm{P}=\frac{\left(\mathrm{h}_{1} \mathrm{D}_{2}-\mathrm{h}_{2} \mathrm{D}_{1}\right)}{2 \mathrm{D}} \frac{\alpha_{1} \Delta \mathrm{T}_{1}\left(\begin{array}{l}1-\mathrm{mn}+\beta_{1} \gamma_{1} \\ -\mathrm{mn} \beta_{2} \gamma_{2}\end{array}\right)}{\mathrm{K} \cosh (\kappa \mathrm{L})} \cosh (\kappa \mathrm{x})$

Where:

$\beta_{1}=\frac{\Delta \mathrm{T}_{1}-\Delta \mathrm{T}_{1}^{\prime}}{\Delta \mathrm{T}_{1}}$

$\beta_{2}=\frac{\Delta \mathrm{T}_{2}-\Delta \mathrm{T}_{2}}{\Delta \mathrm{T}_{2}}$

$\mathrm{F}_{2} \quad \gamma_{1}=\frac{\mathrm{hD}_{1}}{2 \mathrm{~h}_{1} \mathrm{D}}$

$\gamma_{2}=\frac{\mathrm{hD}_{2}}{2 \mathrm{~h}_{2} \mathrm{D}}$

It can be observed that when linear temperature gradient in materials are zero $\left(\Delta \mathrm{T}_{1}=\Delta \mathrm{T}_{1}{ }^{\prime}\right.$ and $\Delta \mathrm{T}_{2}=$ $\left.\Delta \mathrm{T}_{2}{ }^{\prime}\right)$, Eq. 17 and 18 reduces to Eq. 9 and 14, the different uniform temperature models.

\section{MATERIALS AND METHODS}

The analytical and FEM results are presented in graphical form for various combinations of available results based on Suhir's and present models. An actual electronic packaging case was considered where Silicon and Diamond representing die (Layer 1) and die attach 
(Layer 2) respectively. The following input data are used: $\mathrm{E}_{1}=1.88 \times 10^{5} \mathrm{MPa}, \mathrm{v}_{1}=0.3, \alpha_{1}=3 \times 10^{-6} 1 /{ }^{\circ} \mathrm{C}$, $\mathrm{h}_{1}=0.00035 \mathrm{~m}, \mathrm{E}_{2}=4.966 \times 10^{4} \mathrm{MPa}, \mathrm{v}_{2}=0.29, \alpha_{2}=$ $25 \times 10^{-6} 1 /{ }^{\circ} \mathrm{C}, \mathrm{h}_{2}=0.00015 \mathrm{~m}, \mathrm{~L}=0.0025 \mathrm{~m}$. For FEM analysis both $2 \mathrm{D}$ and $3 \mathrm{D}$ models are considered to verify the analytical results. Since the system is symmetric, for 2D half and for 3D one quarter of the model is analyzed. For convenience, the reference is made to Uniform Temperature Model as $\mathrm{M}_{\mathrm{u}}\left(\Delta \mathrm{T}_{1}=\right.$ $\left.\Delta \mathrm{T}_{2}=60^{\circ} \mathrm{C}\right)$, Different Uniform Temperature as $\mathrm{M}_{\mathrm{d}}$ $\left(\mathrm{m}=0.5\right.$ or $\Delta \mathrm{T}_{1}=60^{\circ} \mathrm{C}$ and $\Delta \mathrm{T}_{2}=30^{\circ} \mathrm{C}$ ) and Linear Temperature Gradient Model as $\mathrm{M}_{\mathrm{g}}\left\{\left(\beta_{1}=0.33\right.\right.$ or $\Delta \mathrm{T}_{1}=60^{\circ} \mathrm{C}$ and $\left.\Delta \mathrm{T}_{3}=40^{\circ} \mathrm{C}\right)$ and $\left(\beta_{2}=0\right.$ or $\Delta \mathrm{T}_{2}=30^{\circ} \mathrm{C}$ and $\left.\left.\Delta \mathrm{T}_{4}=30^{\circ} \mathrm{C}\right)\right\}$.

\section{RESULTS AND DISCUSSION}

Figure 5 indicates that the analytical solution for shearing stress has better agreement with 3D FEA compared to 2D FEA almost entire length except near the free end indicating edge effect as expected.

Figure 6 represents shearing stress comparison between uniform temperature model, $\mathbf{M}_{\mathrm{u}}$ and different uniform temperature model, $\mathrm{M}_{\mathrm{d}}$. Analytical comparison indicates that at location $\mathrm{x} / \mathrm{L}=0.8$, for $\mathrm{M}_{\mathrm{d}}$ stress value differences (reduces) by $0.65 \mathrm{MPa}$ compared to $\mathrm{M}_{\mathrm{u}}$, at $\mathrm{x} / \mathrm{L}=0.9$ the difference increases to $4.66 \mathrm{MPa}$ and at $\mathrm{x} / \mathrm{L}=0.96$, the difference further increases to $11 \mathrm{MPa}$ or $57 \%$. FEM comparison between $M_{u}$ and $M_{d}$ in Fig. 6 shows reasonably good agreement with analytical observation at all the locations with the exception near the free end due to edge effect.

Figure 7 represents peeling stress comparison between $\mathrm{M}_{\mathrm{u}}$ and $\mathrm{M}_{\mathrm{d}}$. Analytical comparison shows that at locations $\mathrm{x} / \mathrm{L}=0.8,0.86$ and 0.92 , for $\mathrm{M}_{\mathrm{d}}$ peeling stress reduce by $0.9,2.74$ and $5.34 \mathrm{MPa}$ respectively compared to $\mathrm{M}_{\mathrm{u}}$. Similar trend of variation can also be observed from FEA comparison between the two models in Fig. 7.

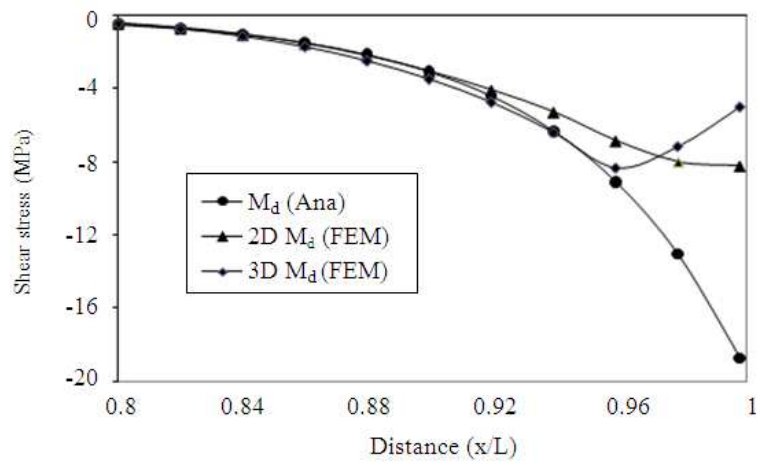

Fig. 5: Shearing stress along the interface for different uniform temperature model, $\mathrm{M}_{\mathrm{d}}$
Figure 8 represents shearing stress for temperature drop ratio, $\beta_{1}$ in layer 1 as a parameter with $\beta_{2}=0$. The results are presented in the vicinity of the free end only, $\mathrm{x} / \mathrm{L}=0.94$ to 1 to visualize the effect of the thickness wise linear temperature gradient in the die. It shows that at location $\mathrm{x} / \mathrm{L}=0.92$, shearing stress for $\mathrm{M}_{\mathrm{g}}$ (for $\beta_{1}=$ 0.33 or $\Delta \mathrm{T}_{1}=60^{\circ} \mathrm{C}, \Delta \mathrm{T}_{3}=40^{\circ} \mathrm{C}$ and $\beta_{2}=0$ or $\Delta \mathrm{T}_{2}=$ $30^{\circ} \mathrm{C}$ ) is almost $0.5 \mathrm{MPa}$ lower compared to $\mathrm{M}_{\mathrm{d}}$ (i.e., $\Delta \mathrm{T}_{1}=60^{\circ} \mathrm{C}$ and $\Delta \mathrm{T}_{2}=30^{\circ} \mathrm{C}$ ). The difference gradually increases to $1.4 \mathrm{MPa}$ or $7.4 \%$ at the free end.

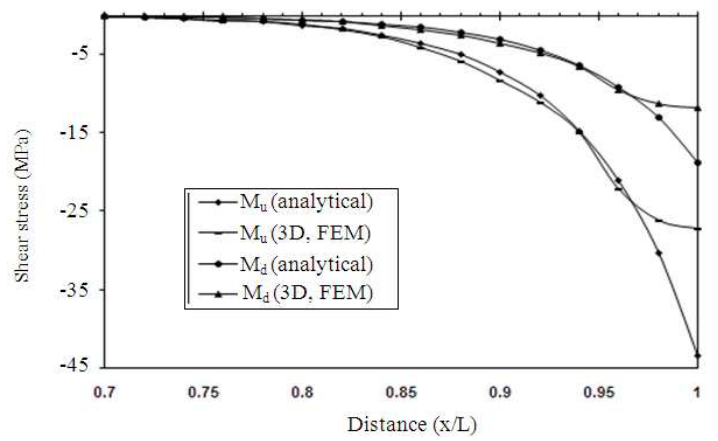

Fig. 6: Comparison of shearing stress between uniform temperature model, $\mathrm{M}_{\mathrm{u}}$ and different uniform temperature model, $\mathrm{M}_{\mathrm{d}}$ along the interface

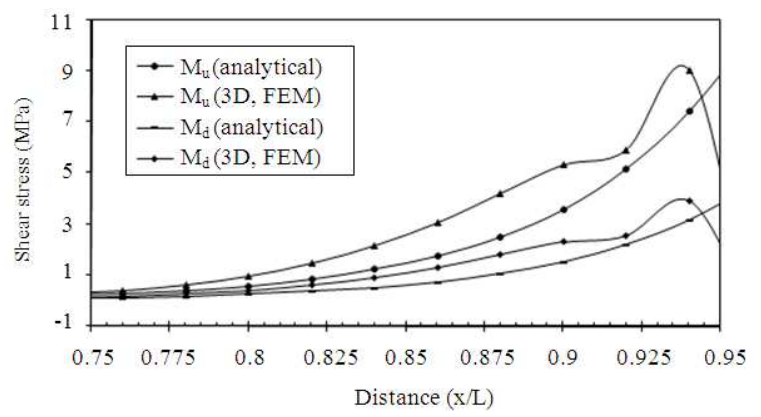

Fig. 7: Comparison of peeling stress between uniform temperature model, $\mathrm{M}_{\mathrm{u}}$ and different uniform temperature model, $\mathrm{M}_{\mathrm{d}}$ along the interface

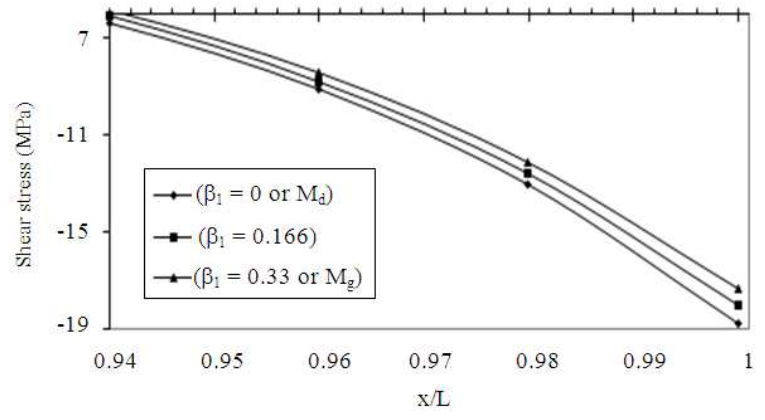

Fig. 8: Shearing stress along the interface with temperature drop ratio $\left(\beta_{1}\right)$ as a parameter 
Am. J. Applied Sci., 7 (6): 829-834, 2010

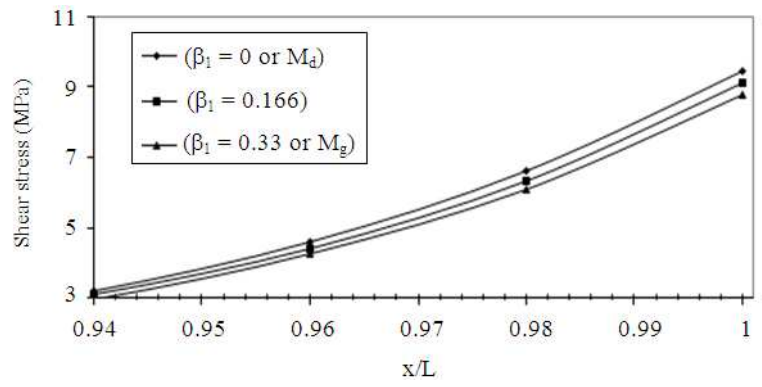

Fig. 9: Peeling stress along the interface with temperature drop ratio $\left(\beta_{1}\right)$ as a parameter

Figure 9 represents peeling stress with temperature drop ratio, $\beta_{1}$ as a parameter. Similar nature of variation can be observed for peeling stress as was seen earlier in shearing stress example in Fig. 8.

\section{CONCLUSION}

Present research upgraded the existing uniform temperature bi-material model to account for different uniform temperature as well as thickness-wise linear temperature gradient in the layers. A simpler method of solution is used to develop this model which does not involve solving integro-differential equations as in the Suhir's method. The following conclusions are summarized:

- 3-D simulation showed better agreement with analytical results compared to 2D model (Fig. 5) especially near the vicinity of the free end for interfacial shearing stress comparison along the interface

- Comparison of analytical results with FEM using the die-die attach bi-material package indicated that the effect of different uniform temperature in the layers reduced both the shearing and peeling stress substantially (for instance $57 \%$ in the case of shearing stress) compared to the uniform temperature model (Fig. 6-7). Thus, it indicates that the different uniform temperature in the layers may influence the interfacial shearing and peeling stresses quite significantly

- Consideration of thickness-wise linear temperature gradient in layer 1 reduced both the shearing and peeling stress values up to $7.4 \%$ (Fig. 8-9) compared to the different uniform temperature model. Therefore, it is concluded that the effect of linear temperature gradient (even in one layer) may influence both the shearing and peeling stresses considerably and should be accounted for carefully while calculating shearing and peeling stresses at the interfaces.

\section{REFERENCES}

Brown, W.D., 1999. Advanced Electronic Packaging. IEEE Press, ISBN: 978-0-471-46609-3, pp: 241-266.

Matthys, L. and G.D. Mey, 1996. An analysis of an engineering model for the thermal mismatch stresses at the interface of a uniformly heated two layer structure. Int. J. Elect. Pack., 19: 323-329.

Mirman, I.B., 1991. Effects of peeling stresses in bimaterial assembly. ASME J. Elect. Pack., 1: 431-433. DOI: $10.1115 / 1.2905433$

Moore, T.D. and J.L. Jarvis, 2003. A simple and fundamental design rule for resisting delamination in biomaterial structures. Microelect. Reliab., 43: 487-494. DOI: 10.1016/S0026-2714(02)00317-7

Moore, T.D. and J.L. Jarvis, 2004. The peeling moment a key rule for delamination resistance in IC assemblies. J. Elect. Pack., 126: 106-109. DOI: $10.1115 / 1.1649240$

$\mathrm{Ru}, \mathrm{C.Q}$, 2002. Interfacial thermal stresses in bimaterial elastic beams: Modified beam models revisited. ASME J. Elect. Pack., 124: 141-146. DOI: $10.1115 / 1.1481037$

Suhir, E., 1986. Stresses in bimetal thermostats. J. Applied Mech., 53: 657-660. DOI: 10.1115/1.3171827

Suhir, E., 1989. Interfacial stresses in bimetal thermostats. ASME J. Applied Mech., 56: 595-600. DOI: $10.1115 / 1.3176133$

Suhir, E., 2009. Predictive analytical thermal stress modeling in electronics and photonics. Applied Mech. Rev., 62: 040801. DOI: 10.1115/1.3077136

Timoshenko, S., 1925. Analysis of bi-metal thermostats. J. Opt. Soc. Am., 11: 233-255. 